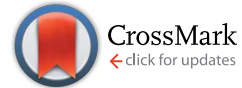

Cite this: RSC Adv., 2015, 5, 32950

\title{
Polysaccharide stabilized nanoparticles for deacidification and strengthening of paper $\uparrow$
}

\author{
Lunjakorn Amornkitbamrung, ${ }^{a}$ Tamilselvan Mohan, ${ }^{\text {aa }}$ Silvo Hribernik, ${ }^{\mathrm{b}}$ \\ Victoria Reichel, ${ }^{c}$ Damien Faivre, ${ }^{c}$ Adriana Gregorova, ${ }^{d}$ Patricia Engel, ${ }^{e}$ Rupert Kargl ${ }^{b}$ \\ and Volker Ribitsch ${ }^{a}$
}

\begin{abstract}
This paper reports an investigation on the use of a highly stable colloidal organic dispersion consisting of a polysaccharide derivative and alkaline nanoparticles for the simultaneous deacidification and strengthening of aged historical wood pulp (HWP) and new paper. Colloidal dispersions of $\mathrm{Mg}(\mathrm{OH})_{2}$ nanoparticles (size ca. $150 \mathrm{~nm}$ ) stabilized by trimethylsilyl cellulose (TMSC) in hexamethyldisiloxane (HMDSO) are employed for paper treatments. The influence of the polymer shell on the morphology of the particles and the stability of the dispersions, and polymer-particles interactions are examined. A correlation between the polymer concentration and stability of the nanoparticles is established. The influence of the particle-polymer coatings on the optical appearance, the $\mathrm{pH}$, the alkaline reserve and the strength of the paper is investigated by $\mathrm{pH}$-measurements of cold-extracts, back-titrations, artificial aging and mechanical testing. Infrared spectroscopy confirmed the irreversible deposition of nanoparticles and TMSC on the paper. The surfaces are evenly coated as confirmed by electron microscopy and contact angle measurements, and the coating does not change the optical appearance of the paper. Results from $\mathrm{pH}$ measurements and back-titrations have proven neutralization of acids and an alkaline reserve of 60 meq $\left[\mathrm{OH}^{-}\right] / 100 \mathrm{~g}$ of paper before aging and $41 \mathrm{meq}\left[\mathrm{OH}^{-}\right] / 100 \mathrm{~g}$ of paper after aging. Upon aging TMSC is hydrolyzed into cellulose and the coated paper exhibits a $20 \%$ higher tensile strength than uncoated paper.
\end{abstract}

Received 24th November 2014 Accepted 23rd March 2015

DOI: 10.1039/c4ra15153d

www.rsc.org/advances consequently accounts for a substantial loss of mechanical strength. ${ }^{2,7,8}$ The process of complete neutralization of acidity in paper and deposition of alkaline components is referred to as 'deacidification'. Up to now, many deacidification methods have been developed to eliminate the detrimental effects of acidity in paper and to simultaneously increase mechanical strength. ${ }^{\mathbf{1 , 3}, \mathbf{9 - 1 2}}$ Despites other existing methods, aqueous solutions and dispersions of alkaline metal hydroxides such as calcium and magnesium have been employed for several decades owing to their high compatibility. ${ }^{\mathbf{1 3 4} \mathbf{1 4}}$ Recently, a nonaqueous process of alcoholic (e.g. ethanol and propanol) dispersions of alkaline nanoparticles (NPs) such as calcium and magnesium hydroxide has been explored for papers, manuscript and archeological woods. ${ }^{\mathbf{1 , 9 , 1 0 , 1 5}}$ These dispersions showed high stability and compatibility and are easy to handle. The nanoparticles cause a sufficient alkaline environment (pH 6-7.5) by turning into mild alkaline species i.e. carbonates. Nonetheless, apolar organic solvents were also used in a variety of processes employing soluble alkaline substances. One of these solvents is hexamethyldisiloxane (HMDSO) used in the well-established Battelle process. ${ }^{16} \mathrm{HMDSO}$ is inert, exhibits low surface tension $\left(15.9 \mathrm{mN} \mathrm{m}^{-1}\right)$ and allowing a sufficient wetting of paper. More importantly it causes a better dimensional stability of paper after treatment due to a very low swelling capacity for cellulose fibers. ${ }^{\mathbf{1 6 , 1 7}}$ Recently this solvent was used 
together with soluble amine-bearing siloxanes for the deacidification and strengthening of paper., ${ }^{3,11,12}$ Although, the above mentioned deacidification methods are versatile in one or the other way, a suitable approach to overcome some drawbacks is to employ substances that are fully compatible with the treated materials.

In this context, a combination of silylated polysaccharides such as trimethylsilyl cellulose (TMSC) and alkaline nanoparticles i.e. $\mathrm{Mg}(\mathrm{OH})_{2}$ could be feasible. TMSC is hydrophobic, soluble in a wide range of organic solvents, and its surface shows a lower water wettability and surface free energy. It has been the focus of cellulose model surface preparation, and was used for the preparation of nanoparticles. ${ }^{\mathbf{1 8 - 2 2}}$ On the other hand, $\mathrm{Mg}(\mathrm{OH})_{2}$ NPs with a narrow size distribution are commercially available, and exhibit many advantages such as a high deacidification efficiency, economic benefits, simplicity of operations and compatibility with natural materials., ${ }^{\mathbf{9 , 2 3 2}}$ The deacidification of acid papers using $\mathrm{Mg}(\mathrm{OH})_{2}$ NPs is not new and it is already well-established in the pioneering work of Giorgi et al. ${ }^{23,24}$ In their work $\mathrm{Mg}(\mathrm{OH})_{2}$ NPs stabilized in alcohol are successfully applied for the deacidification and providing an additional alkaline reserve. While $\mathrm{Mg}(\mathrm{OH})_{2}$ can be dispersed in some alcohols, ${ }^{9,23}$ it is very difficult to disperse them in very apolar organic solvents such as toluene without an additional stabilizer. In such cases, organosoluble TMSC can be used as it imparts a better dispersibility and colloidal stability to nanoparticles due to the hydrophobic trimethylsilyl (TMS) groups and steric repulsion of adsorbed hydrophobic polymer chains. ${ }^{22}$ Moreover, the use of TMSC for deacidification treatment could act as a strengthening component for cellulose fibers in paper.

The aim of this work was therefore to develop an efficient deacidification treatment based on a TMSC stabilized colloidal dispersion of alkaline $\mathrm{Mg}(\mathrm{OH})_{2}$ NPs in HMDSO. The kinetic stability, size and morphology of these particles were investigated by UV-Vis spectroscopy, dynamic light scattering (DLS) and transmission electron microscopy (TEM). Filter and acidic historical wood pulp (HWP) paper were coated with the dispersions. The successful coating of the nanoparticles and long-term effect of the deacidifying treatments were examined by artificial aging tests and studied in detail by electron microscope, colorimetric, infrared (IR) spectroscopy, wettability, alkaline reserve titrations, $\mathrm{pH}$ measurements and testing of the mechanical strength.

\section{Experimental section}

\subsection{Materials and methods}

Magnesium hydroxide nanoparticles $\left(\mathrm{Mg}(\mathrm{OH})_{2}, 99.8 \%\right.$, particle size $<100 \mathrm{~nm}$ ) and hexamethyldisiloxane (HMDSO, 98\%) were purchased from Sigma-Aldrich, Austria. Trimethylsilyl cellulose

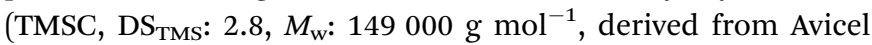
$\mathrm{PH}-101)$ for the stabilization of $\mathrm{Mg}(\mathrm{OH})_{2}$ nanoparticles in HMDSO was purchased from Thüringisches Institut für Textilund Kunststoff-Forschung e.V. (TITK, Rudolstadt, Germany). Two kinds of paper samples were used for the deacidification experiments: $115 \mathrm{~A}$ - type filter paper (made of 100\% cellulose, ash content $=0.06 \%$, surface weight $=80 \mathrm{~g} \mathrm{~m}^{-2}$ ) from Carl
Roth, Germany and historical wood pulp (HWP, made of 50\% ground wood pulp and 50\% chemical pulp, with high lignin content) papers collected from books printed in 1840. All chemicals and materials were used without any purification. Milli-Q water (18.2 $\mathrm{M} \Omega \mathrm{cm}$ at $25{ }^{\circ} \mathrm{C}$ ) from a Millipore water purification system (Billerica, USA) was used for contact angle, $\mathrm{pH}$ and alkaline reserve measurements.

\subsection{Stabilization of $\mathrm{Mg}(\mathrm{OH})_{2} \mathrm{NPs}$ in TMSC}

$1 \mathrm{~g}$ of $\mathrm{Mg}(\mathrm{OH})_{2}$ NPs was added to $0.1,0.5$ and $2 \mathrm{~g}$ of TMSC (dissolved in $100 \mathrm{~mL}$ of HMDSO). The mixtures were sonicated (Elmasonic S40, Elma, Germany) for $30 \mathrm{~min}$ at $25^{\circ} \mathrm{C}$ to obtain a stable colloidal dispersion of TMSC- $\mathrm{Mg}(\mathrm{OH})_{2}$ NPs. The TMSC stabilized $\mathrm{Mg}(\mathrm{OH})_{2}$ NPs were always prepared freshly prior to the impregnation of paper.

\subsection{Coating and peeling of paper}

Coating experiments. A simple dip coating procedure was adapted to deposit the TMSC and the TMSC-Mg(OH $)_{2}$ NPS mixture on paper. Briefly, the papers were cut into $4 \times 5 \mathrm{~cm}^{2}$. For coating, $1 \mathrm{~g}$ of paper (6 paper sheets) were immersed into $200 \mathrm{~mL}$ of $\mathrm{TMSC}-\mathrm{Mg}(\mathrm{OH})_{2}$ dispersion $\left(\mathrm{Mg}(\mathrm{OH})_{2}: 1 \%(\mathrm{w} / \mathrm{v})\right.$, TMSC: $2 \%(\mathrm{w} / \mathrm{v}))$ for $30 \mathrm{~min}$. The mixtures were stirred constantly during the coating process. For comparison, the paper sheets were impregnated in TMSC solution and in HMDSO under the same condition as described above. Afterwards, the paper sheets were taken out and vacuum dried ( 0 bar) at $25{ }^{\circ} \mathrm{C}$ for $24 \mathrm{~h}$.

In addition particles concentration of 0.0625 and $0.25 \%(\mathrm{w} / \mathrm{v})$ were employed for coating of filter and HWP papers in order to tune the final $\mathrm{pH}$ and alkaline reserve (AR) of deacidified papers.

Peeling experiments. To verify the penetration of TMSC$\mathrm{Mg}(\mathrm{OH})_{2} \mathrm{NPs}$ or its aggregates into the inner paper structure we conducted a peeling experiments. For this purpose, HWP papers (uncoated and coated, $4 \times 5 \mathrm{~cm}^{2}$ ) were chosen. Briefly, an adhesive tape was placed on the paper surface (front side), pressed for $1 \mathrm{~min}$ and removed afterwards. Similarly the materials were removed from other side (back) of the paper. This procedure was repeated five times. For analysis, the materials that remained after peeling (i.e. materials, not attached to the adhesive tapes) were used.

\subsection{Accelerated aging of paper}

Paper sheets were aged in order to accelerate the degradation of cellulose following a protocol published elsewhere. ${ }^{10}$ For that purpose, $10 \mathrm{~g}$ of paper sheets (coated/uncoated) were placed in a closed desiccator containing $200 \mathrm{~mL}$ water saturated with $\mathrm{NaCl}$ to maintain the humidity at $75 \% \mathrm{RH}$. The temperature for aging was set to $80{ }^{\circ} \mathrm{C}$. The papers were aged under these conditions for 14 days. After aging, the papers were vacuum dried ( 0 bar) at $25{ }^{\circ} \mathrm{C}$ and conditioned at $23{ }^{\circ} \mathrm{C}$ and $65 \% \mathrm{RH}$ for $24 \mathrm{~h}$. 


\section{Analytical methods}

\subsection{UV-Vis spectroscopy}

The colloidal stability of $\mathrm{Mg}(\mathrm{OH})_{2}$ NPs in HMDSO with and without TMSC was investigated by UV-Vis spectroscopy. $\mathrm{Mg}(\mathrm{OH})_{2}$ (1 g) was added to $100 \mathrm{~mL}$ of HMDSO or TMSC/ HMDSO polymer $(0.1,0.5$ and $2 \mathrm{~g}$ ) and subjected to ultrasonication for $30 \mathrm{~min}$. The kinetic stability of the samples was determined by transmission measurements at a wavelength of $\lambda=600 \mathrm{~nm}$ (optical path length of $10 \mathrm{~mm}$ ). The cuvette was capped to avoid a loss of solvent during the measurements.

\subsection{Dynamic light scattering (DLS)}

The nanoparticles mean hydrodynamic diameter was determined by DLS using a Brookhaven Instruments ZetaPlus zetapotential Analyzer (wavelength: $657 \mathrm{~nm}$, scattering angle: $90^{\circ}$ ). The samples were diluted with HMDSO $\left(\mathrm{Mg}(\mathrm{OH})_{2}: 0.01 \%(\mathrm{w} / \mathrm{v})\right.$, TMSC: $0.02 \%(\mathrm{w} / \mathrm{v}))$. Mean particle diameters were approximated as the effective ( $z$-average) diameters from the bimodal size distribution. The width of the distribution was achieved using the non-negatively constrained least squares (NNLS) method, presuming spherical particle shape and log-normal size distribution. ${ }^{25}$ The measurements were repeated five times.

\subsection{Transmission electron microscope (TEM)}

The morphology and particle size distribution of $\mathrm{Mg}(\mathrm{OH})_{2}$ and TMSC stabilized $\mathrm{Mg}(\mathrm{OH})_{2}$ NPs were analyzed using TEM. For TEM analysis, the samples were prepared by dropping $10 \mu \mathrm{L}$ of dispersion (sonicated for $10 \mathrm{~min}$ ) on 400 mesh carbon coated copper grids (purchased from Plano $\mathrm{GmbH}$, Germany), followed by drying at room temperature. The samples were diluted with HMDSO in the same way as above (Section 3.2). The TEM images were obtained at $120 \mathrm{kV}$ with a ZEISS EM912 at a magnification of 4000-10 000. The particle size was calculated by analyzing the TEM images using the software Image J1.47 and at least 100 particles were chosen for analysis.

\subsection{Field emission scanning electron microscopy (FESEM)}

The morphology of uncoated, coated and peeled paper samples were analyzed by FESEM. A Carl Zeiss FE-SEM SUPRA 35 VP electron microscope was used. The images were recorded with an acceleration voltage of $1 \mathrm{kV}$. The chemical compositions of coated/uncoated paper were examined using an energy dispersive X-ray (EDX) detector (model OXFORD INCA 200, Oxford Instruments Germany, Wiesbaden, Germany). The EDX detector is equipped with a liquid nitrogen cooled X-ray detector (Si(Li) - silicon with lithium) having $10 \mathrm{~mm}^{2}$ crystal area. The working distance for the EDX detector was $8.5 \mathrm{~mm}$ and the electron energy (acceleration voltage) was $10 \mathrm{keV}$. The paper samples were mounted on sample holders and no sputtering on the sample surfaces was performed. For the elemental mapping, a $10 \mathrm{~nm}$ gold layer was sputtered on the sample surface.

\subsection{Colorimetric measurements}

Color measurements of uncoated, coated and aged papers $\left(4 \times 4 \mathrm{~cm}^{2}\right)$ were determined in reflectance mode (spectral range 400-700 nm in $10 \mathrm{~nm}$ steps) using a Spectraflash SF 600 PLUS spectrophotometer (Datacolor) equipped with an integrating sphere. All experiments were conducted on at least three independent samples and on both sides of the sample surface, and an average value was obtained. The sample spot size of $3 \times 3 \mathrm{~cm}^{2}$ was used for the measurement. The color coordinate values $(L, a, b)^{*}$ were calculated in the CIE*LAB1976 Color System, with a D65 standard illuminant and $10^{\circ}$ standard observer. D65 (LAV/Spec. Incl., d/8, D65/10 ${ }^{\circ}$ ). On the basis of measured $\operatorname{CIE}(L, a, b)^{*}$ values, the total color change was determined using the eqn (1). The detailed descriptions of the method can be found elsewhere. ${ }^{26,27}$

$$
\Delta E^{*}=\sqrt{\left(\Delta L^{*}\right)^{2}+\left(\Delta a^{*}\right)^{2}+\left(\Delta b^{*}\right)^{2}}
$$

where $\Delta L^{*}, \Delta a^{*}$ and $\Delta b^{*}$ are the difference between the coated and the uncoated (control) samples.

\subsection{Attenuated total reflection-infrared (ATR-IR) spectroscopy}

A Bruker Alpha ATR-FTIR spectrometer at a scan range of $4000-650 \mathrm{~cm}^{-1}$ was used to analyze the chemical composition of the coated and uncoated papers. A total of 32 scans were performed with a resolution of $4 \mathrm{~cm}^{-1}$.

\subsection{Static contact angle (SCA) measurements}

The water wettability of coated and uncoated papers were measured by using a OCA15+ contact angle measurement system (Dataphysics, Germany) with the sessile drop method and a drop volume of $3 \mu \mathrm{l}$. All measurements were carried out at room temperature. Determination of the SCA was based on the analysis of the drop shape by the Young-Laplace method and was performed with the software provided by the manufacturer (software version SCA 20). All the measurements were performed on at least three independent substrates with a minimum of ten drops per surface and an average value was calculated.

\subsection{Alkaline reserve and $\mathrm{pH}$ determination}

The alkaline reserve (AR) (meq $\left(\mathrm{OH}^{-}\right) / 100 \mathrm{~g}$ paper) was determined by back-titration according to the standard method ASTM D4988-96R01. Briefly, papers ( $1 \mathrm{~g}$ ) were cut into $5 \times 5 \mathrm{~mm}^{2}$ and placed it in Erlenmeyer flask $(125 \mathrm{~mL})$ containing $25 \mathrm{~mL}$ of MQ-water and $20 \mathrm{~mL}$ of $0.1 \mathrm{M} \mathrm{HCl}$. The mixtures were heated to boiling. After boiling it for $1 \mathrm{~min}$ it was cooled down to room temperature. Following this three drops of methyl red indicator were added. The mixtures were then titrated with $0.1 \mathrm{M} \mathrm{NaOH}$ up to the end point (color change from red to first lemon-yellow). The alkaline reserve was determined using the eqn (2) and (3)

$$
\begin{aligned}
& \text { Alkalinity as } \mathrm{Mg}(\mathrm{OH})_{2}= \\
& \qquad \frac{\left[\left(V_{\mathrm{HCl}} \times N_{\mathrm{HCl}}\right)-\left(V_{\mathrm{NaOH}} \times N_{\mathrm{NaOH}}\right)\right] \times 0.029 \times 100}{\mathrm{DW}}
\end{aligned}
$$


where 0.029 is the milliequivalent weight of $\mathrm{Mg}(\mathrm{OH})_{2}$ and $\mathrm{DW}$ is the dry weight of the specimen (in g).

Alkaline reserve $\left(\right.$ meq $\left[\mathrm{OH}^{-}\right] / 100 \mathrm{~g}$ paper mass $)=$
$\frac{\left[\left(V_{\mathrm{HCl}} \times N_{\mathrm{HCl}}\right)-\left(V_{\mathrm{NaOH}} \times N_{\mathrm{NaOH}}\right)\right]}{\text { Dry weight of paper }(\mathrm{g})} \times 100$

The cold-extract $\mathrm{pH}$ of the papers was determined according to the standard method TAPPI T509 om-88, scaled down to $0.5 \mathrm{~g}$ of paper. Briefly, papers $(0.5 \mathrm{~g})$ were cut into $5 \times 5 \mathrm{~mm}^{2}$ and placed it in $50 \mathrm{~mL}$ beaker. Then, $5 \mathrm{~mL}$ of MQ-water was added and the mixtures were macerated with a flattened glass stirring rod until the papers were wet. Afterwards, $30 \mathrm{~mL}$ of MilliQ-water was added, stirred for $1 \mathrm{~h}$, covered with a watch glass covered, allowed to stand for few minutes at room temperature, and the $\mathrm{pH}$ was measured. All the experiments were carried out at least three times.

For determination of $\mathrm{pH}$ and alkaline reserve for peeled samples, at least $1 \mathrm{~g}$ of paper were collected (from the peeling experiments as mentioned in Section 2.3) and cut into $5 \times 5 \mathrm{~mm}^{2}$. Several coated paper sheets $\left(4 \times 5 \mathrm{~cm}^{2}\right)$ were used for peeling to obtain at least $1 \mathrm{~g}$ of material.

\subsection{Mechanical properties}

The tensile strength at maximum (MPa) and the tensile strain at break (\%) of the papers were measured according to the standard method TAPPI T494 om-01 using a Shimadzu AGS-X electromechanical universal testing machine. ${ }^{28}$ For testing, the papers were cut into a size of $4 \mathrm{~mm} \times 5 \mathrm{~cm}$ and vertically mounted with two clamps with $2.5 \mathrm{~cm}$ distance between the clamps. Papers were tested at a speed of $1 \mathrm{~mm} \mathrm{~min}^{-1}$ with a $5 \mathrm{kN}$ load cell. At least ten experimental runs were carried out and average values and standard deviations were calculated. All papers were conditioned at $23{ }^{\circ} \mathrm{C}$ and $65 \% \mathrm{RH}$ for $24 \mathrm{~h}$ before the test.

\section{Results and discussion}

\subsection{Kinetic stability, particle size and morphology of unmodified and TMSC stabilized $\mathrm{Mg}(\mathrm{OH})_{2}$ NPs}

For many applications, an important goal is to enhance the stability of nanoparticle dispersions during transportation storage and use. One common strategy to control the aggregation of nanoparticles in solution is to add polymers, which act as a steric stabilizer preventing uncontrolled aggregation. ${ }^{29,30} \mathrm{At}$ present synthetic polymers are employed more frequently. ${ }^{29,31}$ In our case, we have chosen TMSC as a stabilizer since polysaccharides in general are biocompatible and beneficial for paper conservation. The kinetic stability of the nanoparticles in solution can be easily examined by UV-Vis spectroscopy. Fig. 1 shows the UV-Vis absorbance $(600 \mathrm{~nm})$ of $\mathrm{Mg}(\mathrm{OH})_{2}(1 \%, \mathrm{w} / \mathrm{v})$ dispersed in HMDSO with and without TMSC as a stabilizer $(0.1,0.5$ and $2 \%, \mathrm{w} / \mathrm{v})$. Pure $\mathrm{Mg}(\mathrm{OH})_{2}$ NPs dispersed in HMDSO settles down rapidly within the first minutes as indicated by a sudden drop in absorbance (Fig. 1a). In contrast, $\mathrm{Mg}(\mathrm{OH})_{2} \mathrm{NPs}$ stabilized with TMSC shows a much higher stability (absorbance above 80\%) (Fig. 1b-d). This is further shown by the photographs in Fig. 1 (insert). The pure $\mathrm{Mg}(\mathrm{OH})_{2}$ NPs dispersed in HMDSO solvent completely sediment while TMSC $(2 \%, \mathrm{w} / \mathrm{v})$ stabilized $\mathrm{Mg}(\mathrm{OH})_{2}$ NPs remained as a stable colloidal dispersion. Obviously, with an increase in TMSC concentration the particle dispersibility and colloidal stability is increased, indicating an enhanced interaction between the particles and the polymer. TMSC offers steric repulsion and hydrophobization of nanoparticles due to its high molecular weight and its trimethylsilyl (TMS) groups which prevent the particles from uncontrolled aggregation. Although a slight and constant decrease in absorbance is noticeable for particles stabilized with lower TMSC concentration $(0.1-0.5 \%, \mathrm{w} / \mathrm{v})$, the absorbance is nearly constant at a high TMSC concentration $(2 \%, \mathrm{w} / \mathrm{v})$ throughout the whole duration of the test. It should be noted that the $3 \mathrm{~h}$ time-span of the test is considered sufficient for practical applications. For further analysis and deacidification, dispersions containing $1 \%(\mathrm{w} / \mathrm{v}) \mathrm{Mg}(\mathrm{OH})_{2}$ and $2 \%(\mathrm{w} / \mathrm{v})$ TMSC are employed since they show high colloidal stability and contain sufficient amounts of alkaline particles.

The mean particle size of $\mathrm{Mg}(\mathrm{OH})_{2} \mathrm{NPs}(1 \%, \mathrm{w} / \mathrm{v})$ dispersed in HMDSO and in TMSC solution ( $2 \%, \mathrm{w} / \mathrm{v})$, measured by DLS, were found to be $838 \pm 15$ and $150 \pm 3 \mathrm{~nm}$. Besides that, TEM analysis was performed to determine the particles size in dry condition and compared it with the results from DLS measurements. TEM images of $\mathrm{Mg}(\mathrm{OH})_{2} \mathrm{NPs}(1 \%, \mathrm{w} / \mathrm{v})$ dispersed in HMDSO and in TMSC solution $(2 \%, \mathrm{w} / \mathrm{v})$, and their corresponding particle size distributions in the dry state are shown in Fig. 2. As expected, $\mathrm{Mg}(\mathrm{OH})_{2}$ NPs dispersed in polymer free HMDSO shows a clear agglomeration of spherical-shaped particles with average diameter of $46 \pm 2 \mathrm{~nm}$ (a and b). In the presence of TMSC an agglomeration of NPs is still visible and the spherical morphology is less pronounced (c). Interestingly, the size of the single particles remain unchanged $(45 \pm 3 \mathrm{~nm}, \mathrm{~d})$ after hydrophobisation with TMSC. Obviously the particles measured by TEM are much smaller than the mean particle size measured by DLS. The latter measure the mean solvodynamic diameter, whereas TEM give the single and vacuum dried particles. It is well-known that the hydrodynamic size of the particles which are dispersed in liquids are usually larger than the primary particle

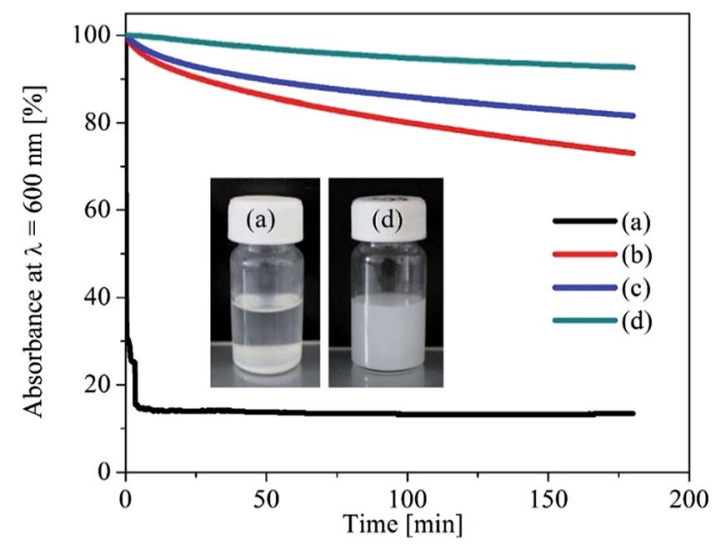

Fig. 1 Absorbance of $\mathrm{Mg}(\mathrm{OH})_{2} \mathrm{NPs}$ dispersed in $\mathrm{HMDSO}$ (a) and in TMSC ((b) $0.1 \% \mathrm{w} / \mathrm{v}$, (c) $0.5 \% \mathrm{w} / \mathrm{v}$, (d) $2 \% \mathrm{w} / \mathrm{v}$ ) at $600 \mathrm{~nm}$ wavelength. 
size i.e. single particle, as reported in many other studies. ${ }^{32-34}$ From that viewpoint, we can propose that during DLS analysis, an agglomerate of many single particles $\left(\mathrm{Mg}(\mathrm{OH})_{2}\right.$ or TMSC$\left.\mathrm{Mg}(\mathrm{OH})_{2} \mathrm{NPs}\right)$ are measured as one large particles. However, during TEM analysis the average particle size of the individual particles that form an agglomerate is determined.

\subsection{Optical appearance of coated and aged papers}

Accelerated aging is one of the primary interests in library and archival preservation science in order to determine the long term effect of conservation treatment and the life span of the paper coated with the deacidifying components. Such tests are usually performed at elevated temperature and constant relative humidity. In our study, we conducted the accelerated aging test at $80{ }^{\circ} \mathrm{C}$ and at $75 \% \mathrm{RH}$ for both filter and HWP papers. Filter paper is used as a quasi-standard in research and in the paper conservation and restoration. Moreover, filter paper is chemically and structurally somehow similar to HWP paper, and is nearly included as a standard testing material in the evaluation of all new deacidification methods therefore. Due to the above mentioned properties, filter papers are chosen as a reference paper although it does not contain any sizing components, in our case, for analysis of the degradation of cellulose after the deacidification and artificial aging.

The macroscopic images of the uncoated and coated filter and HWP papers before and after artificial aging are shown in Fig. 3. It is obvious that coating with either TMSC or TMSC stabilized $\mathrm{Mg}(\mathrm{OH})_{2}$ NPs (and/or aggregates) does not cause visible deposits or other changes in the dimensions or appearance of the uncoated papers. This is further supported by the finding from the color measurements (see Section 4.3). However, a color change i.e. yellowing occurs already on the uncoated papers due to aging. This effect is also visible on papers that are coated with TMSC and TMSC-Mg(OH $)_{2}$ NPs. As mentioned above, an important reaction during aging is the
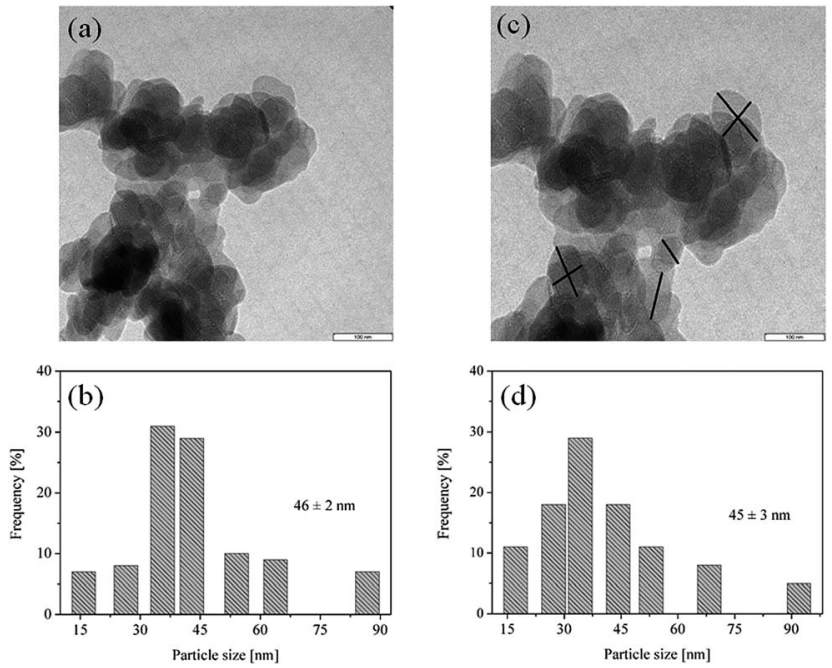

Fig. 2 TEM images (top) and particle size distribution (bottom) of $\mathrm{Mg}(\mathrm{OH})_{2}$ NPs dispersed in HMDSO (a and b) and in HMDSO/TMSC (2\%, $\mathrm{w} / \mathrm{v})(\mathrm{c}$ and $\mathrm{d}$ ). hydrolytic degradation of cellulose macromolecules due to acidity in paper. The yellowing of paper upon aging can be attributed to the presence of chromosphores formed from the degradation of one or more components (like cellulose, lignin and hemicellulose). ${ }^{35}$ However the oxidation of cellulose cannot be avoided during an accelerated aging (at temperature of $80{ }^{\circ} \mathrm{C}$ and at $75 \% \mathrm{RH}$ ), leading to an increased acidity followed by yellowing in paper. Upon aging the papers coated with mixtures of TMSC/deacidifying components are turned into more yellow in color compared to uncoated and aged papers. Even though this can be seen as one drawback of our method, the additional yellowing can be prevented or avoided by controlling the final $\mathrm{pH}$ of the paper by coating with a lower particles concentration (see Section 4.3 and 4.7 ).

\subsection{Colorimetric measurements}

To verify the discoloration of uncoated and coated papers (before and after aging) colorimetric measurements were performed. The results of the CIE color coordinates $(L, a, b)^{*}$ are presented in Table 1 . The results showed that the discoloration (i.e. yellowing) occurred already on uncoated and aged papers. Obviously, filter paper showed more yellowing $\left(\Delta E^{*}=13.4\right)$ than that of HWP one $\left(\Delta E^{*}=10.3\right)$, indicating that uncoated filter paper undergoes a fast degradation and more susceptible to oxidation. After coating with TMSC and aged no significant changes in yellowing is observed. However, the yellowing is increased up to $4 \%\left(\Delta E^{*}=14.1\right)$ and $18 \%\left(\Delta E^{*}=12.5\right)$ for filter and HWP paper compared to uncoated and aged papers. The increased yellowing for HWP paper maybe due to the high $\mathrm{pH}$ (9) obtained by TMSC- $\mathrm{Mg}(\mathrm{OH})_{2}$ NPs coating (Table 5 and $\mathrm{S} 1$, see ESI $\dagger$ ). As reported by other authors, a pH value of above 9 can be dangerous for oxidized papers, leading to more degradation, and consequently to more yellowing. ${ }^{2}$ To verify this HWP paper (coated $0.25 \%(\mathrm{w} / \mathrm{v})$ particles concentration) that showed a value close to neutral $\mathrm{pH}(7.6 \pm 0.3$, see Section 4.7$)$ was chosen and (a)

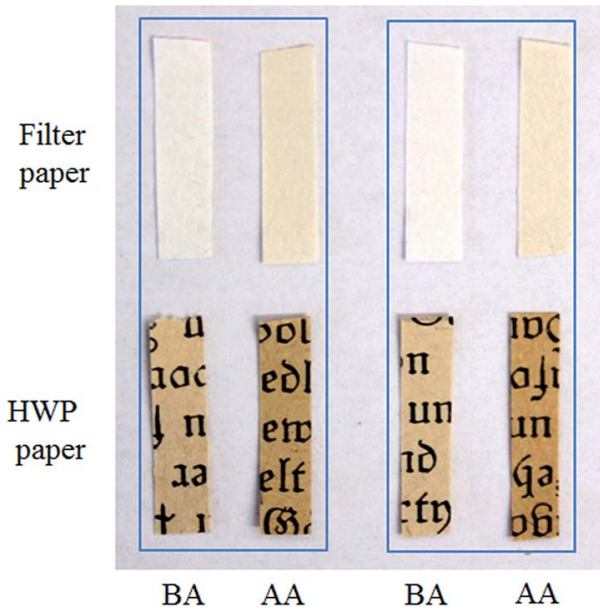

(c)

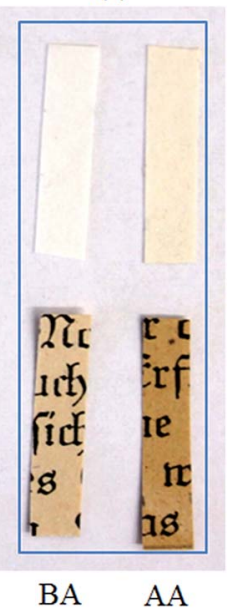

Fig. 3 Uncoated and treated paper sheets before and after artificial aging. (a) Uncoated papers, (b) papers coated with TMSC and (c) papers coated with TMSC-Mg(OH) 2 NPs. BA - before aging and AA after aging. 
Table 1 CIE color coordinates of uncoated and coated papers

\begin{tabular}{|c|c|c|c|c|c|c|c|c|}
\hline Samples & \multicolumn{3}{|c|}{ Filter paper } & $\Delta E^{*}$ & \multicolumn{3}{|c|}{ HWP paper } & $\Delta E^{*}$ \\
\hline Uncoated, aged & 88.9 & 3.0 & 14.6 & 13.4 & 73.4 & 5.7 & 20.4 & 10.3 \\
\hline TMSC coated & 96.3 & 0.01 & 3.9 & 0.0 & 82.3 & 3.1 & 17.1 & 0.0 \\
\hline TMSC coated, aged & 87.6 & 2.7 & 13.1 & 13.0 & 73.4 & 6.1 & 21.1 & 10.2 \\
\hline
\end{tabular}

subjected to artificial aging as mentioned above. The results showed that the yellowing $\left(\Delta E^{*}=10 \pm 0.1\right)$ remained unchanged compared to uncoated and aged paper $\left(\Delta E^{*}=10.3\right.$ \pm 0.1 ), while it decreased to $28 \%$ compared to HWP paper (Tables S1 and S2, see ESI $\dagger$ ) which is coated with higher particles concentration $(1 \%, \mathrm{w} / \mathrm{v}$ ) and had a $\mathrm{pH}$ value of 9 (see Table 5). Similar results are obtained for filter paper whose $\mathrm{pH}$ was $7.5 \pm 0.1$ after coating with $0.0625 \%(\mathrm{w} / \mathrm{v})$ particles concentration. These results confirm that the yellowing can be avoided for deacidified papers having neutral $\mathrm{pH}$ upon aging. Moreover, it can be noticed that the brightness $\left(L^{*}\right)$ value is not changed for coated and non-aged papers, confirming that the color of the papers is retained after the application of our coating. In general, the yellowing is caused by the formation of chromophore, which is the results of degradation of one or more components present in HWP paper as mentioned before.

\subsection{Microscopic morphology of the coatings}

The SEM images of the uncoated filter and HWP paper are depicted in Fig. 4a. It can be seen that both materials have the common fibrillar microstructure. A certain smoothening effect of the fiber surface can be observed after TMSC coating (b). The images of TMSC coated papers after aging are shown in the ESI (ESI, Fig. S1†) and showed clumps of aggregates deposited on the fiber surfaces of HWP paper at least compared to the nonaged samples. By treating filter and HWP paper with the TMSC stabilized nanoparticle dispersions homogeneous particle deposits are immobilized on the fiber surfaces (c). Almost full coverage of a thin particle layer is obtained. The thickness of this layer is of importance since transparency of the coatings is necessary and no white deposits are visible. After aging for two weeks at $80{ }^{\circ} \mathrm{C}$, no morphological changes of the particle coatings are observed and $\mathrm{Mg}(\mathrm{OH})_{2}$ is retained on the surface (d).

To verify the deposition or distribution of particles at the inner surfaces of paper the coated materials from the top few layers of paper were peeled off using an adhesive tape (see Section 2.3) and the samples that remained after peeling were analyzed by SEM. The SEM micrographs of uncoated and coated papers after peeling-off one and five times are shown in Fig. 5. It can be seen that the fibrillar structures of peeled samples are changed ( $\mathrm{a}$ and $\mathrm{b}$ ) comparing to the original ones (Fig. 4a, right). For coated papers whose surfaces were peeled-off once, smaller and larger agglomerated nanoparticles are visible as indicated by the arrows (c). Interestingly, this is also noticeable on surfaces that were peeled-off five times (d). This is further supported by EDX elemental mapping (Fig. S3 and S4, see ESI $\dagger$ ), which clearly shows the presence of magnesium and silicon (as indicated by the bright spots) in one time peeled as well as in five times peeled samples similar to unpeeled coated samples (Fig. S2, see ESI $\dagger$ ), but to a lesser extent. The results suggest that the functionalized alkaline particles are small enough to penetrate/diffuse through the pores of paper in the liquid environment. The penetration of the nanoparticles into the core of the paper is also verified by water contact angle measurements (see Section 4.6). Further it can be concluded that the method allows to deposit alkaline components inside the paper by a simple diffusion process, which is necessary to ensure a
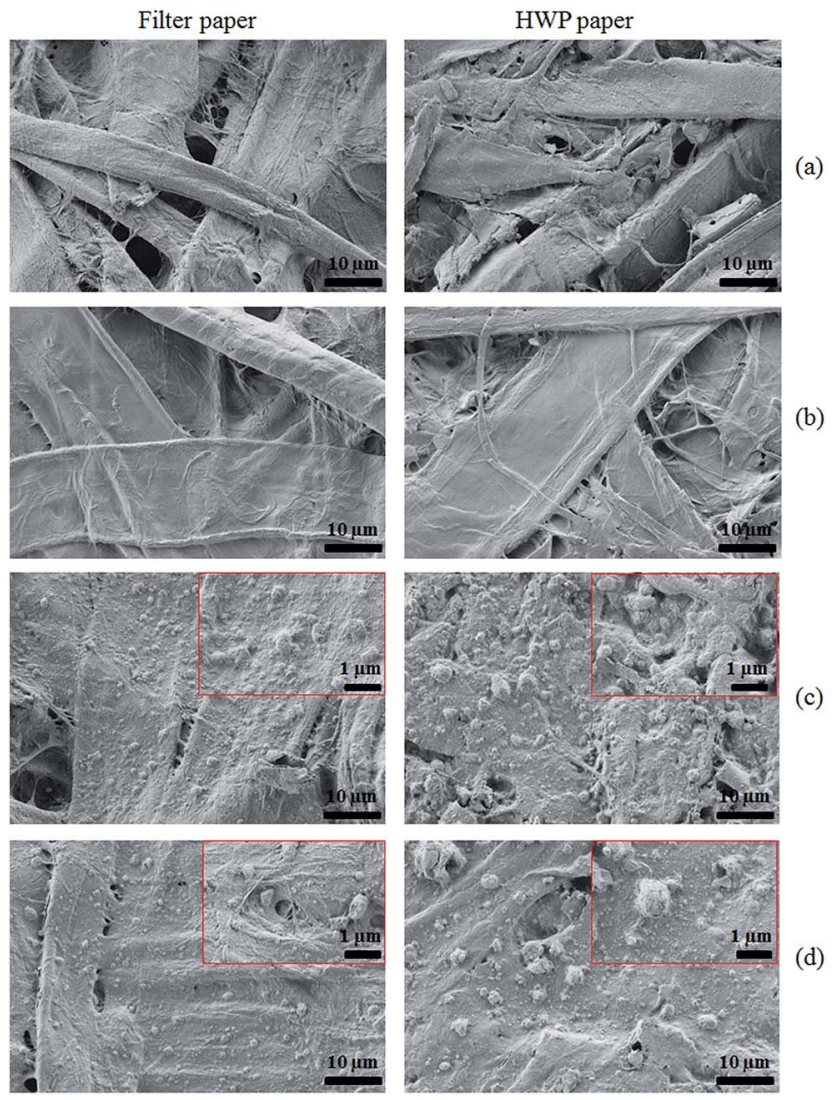

(d)

Fig. 4 SEM micrographs of (a) uncoated paper, (b) TMSC coated before aging, (c) TMSC-Mg(OH) 2 coated before aging, (d) TMSC$\mathrm{Mg}(\mathrm{OH})_{2}$ NPs coated after aging. 
complete neutralization of acidity and a longer prevalence of treatment.

The layer thickness and the mass loss of the peeled samples were also measured and the results are presented in Table 2. As expected, both filter and HWP paper showed a reduced layer thickness and mass as a result of peeling. For filter paper the thickness and the mass are decreased to 14 and $33.5 \%$ after one time peeling. While the HWP paper showed a $14 \%$ reduction in film thickness similar to filter paper, the mass is decreased to $20.5 \%$. Whereas, five times peeling resulted in 36 and $29 \%$ reduction in layer thickness for filter and HWP paper, and the mass loss is close to $40 \%$ for both papers.

Table 3 shows the amount of magnesium and silicon present in the uncoated and coated papers before and after aging, obtained from EDX analysis (in at.\%). While no silicon is detected on uncoated filter and HWP paper, the papers coated with TMSC show the presence of silicon (filter paper: $2.9 \pm 0.2$ at. $\%$, HWP paper: $4.8 \pm 0.5$ at. $\%$ ) confirming that the papers are successfully coated with TMSC. Interestingly the HWP paper shows higher amounts of deposited TMSC. A plausible reason can be that the old HWP paper contains more pores and exhibits a higher surface roughness, allowing the uptake of more TMSC. An enhanced TMSC deposition is noticed (filter paper: $7.9 \pm 0.3$ at. $\%$, HWP paper: $11.2 \pm 0.3$, at.\%) when dispersion containing $\mathrm{Mg}(\mathrm{OH})_{2}$ NPs are employed. In this case, it can be assumed that $\mathrm{Mg}(\mathrm{OH})_{2}$ NPs with a larger surface area facilitates the incorporation of higher amounts of TMSC. The papers that are coated with TMSC and subjected to accelerated aging show no silicon, demonstrating that the coated TMSC is hydrolyzed into cellulose. Higher humidity and temperature can hydrolyze TMSC into cellulose by cleaving of $\mathrm{O}-\mathrm{Si}$ bonds from the TMSC backbone. Upon aging TMSC will be converted into corresponding silanol, which undergoes condensation reaction to give hexamethyldisiloxane (HMDSO). The later compound with low surface tension is rather volatile and can be removed from the surface as soon it is formed..$^{20}$ In contrast for papers coated with TMSC- $\mathrm{Mg}(\mathrm{OH})_{2}$ NPs no significant reduction in silicon is noted after aging. This implies that the
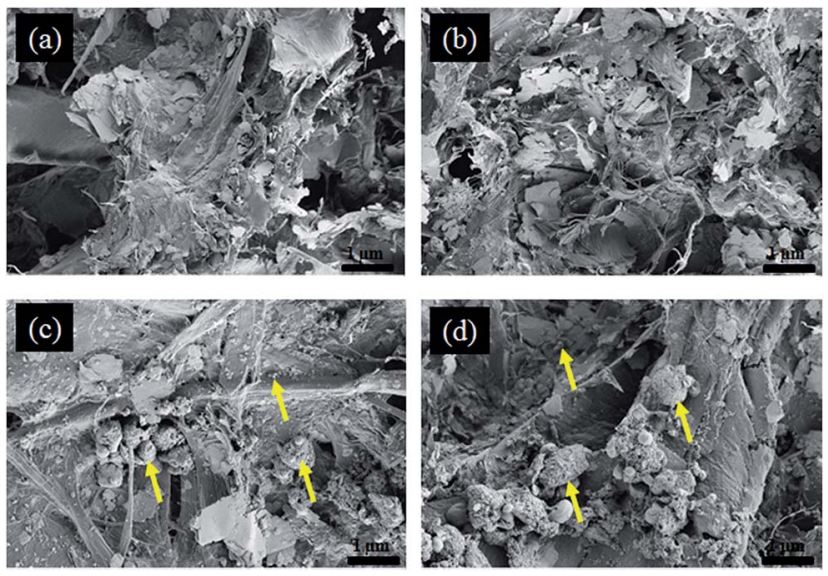

Fig. 5 SEM micrographs of uncoated (top) and TMSC $-\mathrm{Mg}(\mathrm{OH})_{2} \mathrm{NPS}$ coated (bottom) HWP paper. Once peeled ( $a$ and $c$ ), and five times peeled $(b$ and $d)$.
Table 2 The film thickness and mass loss of the TMSC $-\mathrm{Mg}(\mathrm{OH})_{2} \mathrm{NPS}$ coated and uncoated papers before aging

\begin{tabular}{llllll}
\hline & Filter paper & & & HWP paper & \\
\cline { 5 - 6 } Peel & Thickness $(\mu \mathrm{m})$ & Mass loss $(\%)$ & & Thickness $(\mu \mathrm{m})$ & Mass loss $(\%)$ \\
\hline 0 & $140 \pm 2$ & - & $140 \pm 2$ & - \\
1 & $120 \pm 10$ & 34 & $120 \pm 2$ & 33 \\
5 & $90 \pm 10$ & 39 & $100 \pm 10$ & 38
\end{tabular}

presence of $\mathrm{Mg}(\mathrm{OH})_{2}$ essentially prevents complete hydrolysis of TMSC, most likely due to sterical hindrance and reduced accessibility for water. The filter and HWP paper coated with TMSC- $\mathrm{Mg}(\mathrm{OH})_{2}$ NPs shows 8 and $22 \%$ reduction in magnesium after aging, indicating that some $\mathrm{Mg}(\mathrm{OH})_{2}$ is converted into the carbonate form by reacting with carbon-di-oxide $\left(\mathrm{CO}_{2}\right)$ or into its corresponding $\mathrm{MgSO}_{4}$ salt upon neutralization with acids. ${ }^{23}$ It has to be noted that distribution of atomic ratio of magnesium is less in $\mathrm{MgCO}_{3}$ or in $\mathrm{MgSO}_{4}$ compared to $\mathrm{Mg}(\mathrm{OH})_{2}$. Therefore, a lower magnesium content is detected by EDX for papers coated with TMSC- $\mathrm{Mg}(\mathrm{OH})_{2}$ NPs after aging.

\subsection{Attenuated total reflection infrared spectroscopy (ATR- IR) analysis}

The ATR-IR spectra of filter and HWP paper of the different coatings are shown in Fig. 6. Compared to uncoated paper (a), peaks for the $\mathrm{C}-\mathrm{Si}$ rocking vibrations (at 757, 1250 and $840 \mathrm{~cm}^{-1}$ ) are observed for papers coated with TMSC and TMSC-Mg(OH $)_{2}$ NPs (b and c). In addition the peaks corresponding to $\mathrm{O}-\mathrm{H}$ stretching vibrations of $\mathrm{Mg}(\mathrm{OH})_{2}$ NPs are detectable at $3695 \mathrm{~cm}^{-1}$ (c). Interestingly, the $\mathrm{C}-\mathrm{Si}$ peaks disappeared completely for papers coated with TMSC (without $\mathrm{Mg}(\mathrm{OH})_{2}$ NPs) after aging (Fig. S5, see ESI $\dagger$ ), confirming that during aging TMSC is hydrolyzed into cellulose, by cleavage of the O-Si bond from the TMSC backbone. ${ }^{19-21}$ This data supports the finding from the EDX analysis that also showed no detection of silicon for aged TMSC coated paper samples. In contrast the $\mathrm{C}-\mathrm{Si}$ bonds are still present in TMSC-Mg$(\mathrm{OH})_{2}$ NPs coated paper (d). The presence of a dense $\mathrm{Mg}(\mathrm{OH})_{2}$ layer obviously protects the TMSC to be hydrolyzed during aging. Again, the latter results correlate very well with the EDX analysis where no major reduction in silicon content is observed for the TMSC- $\mathrm{Mg}(\mathrm{OH})_{2}$ NPs coated paper after aging (see Table 3 ). The results also showed no additional peaks, before and after aging, for the formation of carbonate ion $\left(\mathrm{CO}_{3}{ }^{2-}\right)$, implying that no conversion is taken place from $\mathrm{Mg}(\mathrm{OH})_{2}$ to magnesium carbonate $\left(\mathrm{MgCO}_{3}\right)$. A likely explanation is that the protective TMSC layer may inhibit the carbonate formation or the concentration of $\mathrm{MgCO}_{3}$ is too low to be detected (if it is formed), creating a less safe environment compared to the one which could be generated by $\mathrm{MgCO}_{3}$.

\subsection{Contact angle measurements}

The wettability of paper coated with TMSC and TMSC-Mg(OH $)_{2}$ NPs before and after aging was determined by water contact 
Table 3 Magnesium and silicon content of uncoated and coated papers, obtained from EDX analysis. The values were obtained from the average of six independent measurements from two samples. For clarity reasons the values of other elements are given in the ESI (Tables S3 and S4)

\begin{tabular}{|c|c|c|c|c|}
\hline & \multicolumn{2}{|l|}{ Filter paper } & \multicolumn{2}{|l|}{ HWP paper } \\
\hline & $\mathrm{Mg}($ at. $\%)$ & Si (at.\%) & $\mathrm{Mg}($ at.\%) & Si (at.\%) \\
\hline TMSC coated (before aging) & n.d & $2.9 \pm 0.2$ & n.d & $4.8 \pm 0.5$ \\
\hline TMSC coated (after aging) & n.d & n.d & n.d & n.d \\
\hline TMSC-Mg(OH $)_{2}$ NPs coated (before aging) & $11.8 \pm 0.4$ & $7.9 \pm 0.3$ & $23.2 \pm 1.0$ & $11.2 \pm 0.3$ \\
\hline
\end{tabular}

angle measurements (Table 4). Uncoated filter paper is obviously completely wetted. In contrast, uncoated HWP paper is highly hydrophobic (CA) $\mathrm{H}_{2} \mathrm{O}: 125^{\circ}$. This can be attributed to the presence of different components in paper, such as lignin and sizing agents, ${ }^{36}$ and a generally low moisture content. After coating with TMSC, a high (CA) $\mathrm{H}_{2} \mathrm{O}: 125^{\circ}$ is noticed for both papers confirming the successful deposition of TMSC on filter paper and supporting the findings from the EDX analysis and ATR-IR measurements. Higher (CA) $\mathrm{H}_{2} \mathrm{O}$ values are well-known for TMSC coated surfaces as reported elsewhere. ${ }^{37,38}$ As mentioned above, aging results in the cleavage of $\mathrm{O}-\mathrm{Si}$ bonds and leads to cellulose formation with higher water wettability. ${ }^{19,39}$ Upon aging the surface of TMSC coated filter paper becomes again completely hydrophilic $\left((\mathrm{CA}) \mathrm{H}_{2} \mathrm{O}\right.$ not measurable) and HWP paper treated in the same way also has a much lower $\left((\mathrm{CA}) \mathrm{H}_{2} \mathrm{O}\right.$ confirming the hydrolysis of TMSC. Filter paper coated with TMSC-Mg(OH $)_{2}$ NPs shows similar $(\mathrm{CA}) \mathrm{H}_{2} \mathrm{O}$ as pure TMSC coatings confirming the presence of polymer and particles. After aging contact angles are not decreased on these coatings. These results are comparable with the data derived from IR measurements where the $\mathrm{C}-\mathrm{Si}$ peaks are still present on the aged paper. Retaining the hydrophobicity even after aging would be advantageous for paper conservation since a hydrophobic paper surface could reduce the uptake of moisture from the surrounding environment. However the formation of cellulose during aging does also not impose any risk on paper and can be seen advantageous in terms of the materials' compatibility.

As mentioned in Section 4.4, contact angles measurements were performed to confirm the penetration of TMSC-Mg $(\mathrm{OH})_{2}$ NPs into the inner structure of the peeled samples. For this purpose, the (CA) $\mathrm{H}_{2} \mathrm{O}$ are measured for both filter and HWP paper (uncoated and coated) that were peeled for five times. As expected no differences in $(\mathrm{CA}) \mathrm{H}_{2} \mathrm{O}$ for peeled coated $\left(142 \pm 5^{\circ}\right)$ and uncoated $\left(142 \pm 5^{\circ}\right)$ HWP paper is observed. This is due to the fact that HWP paper contains different hydrophobic

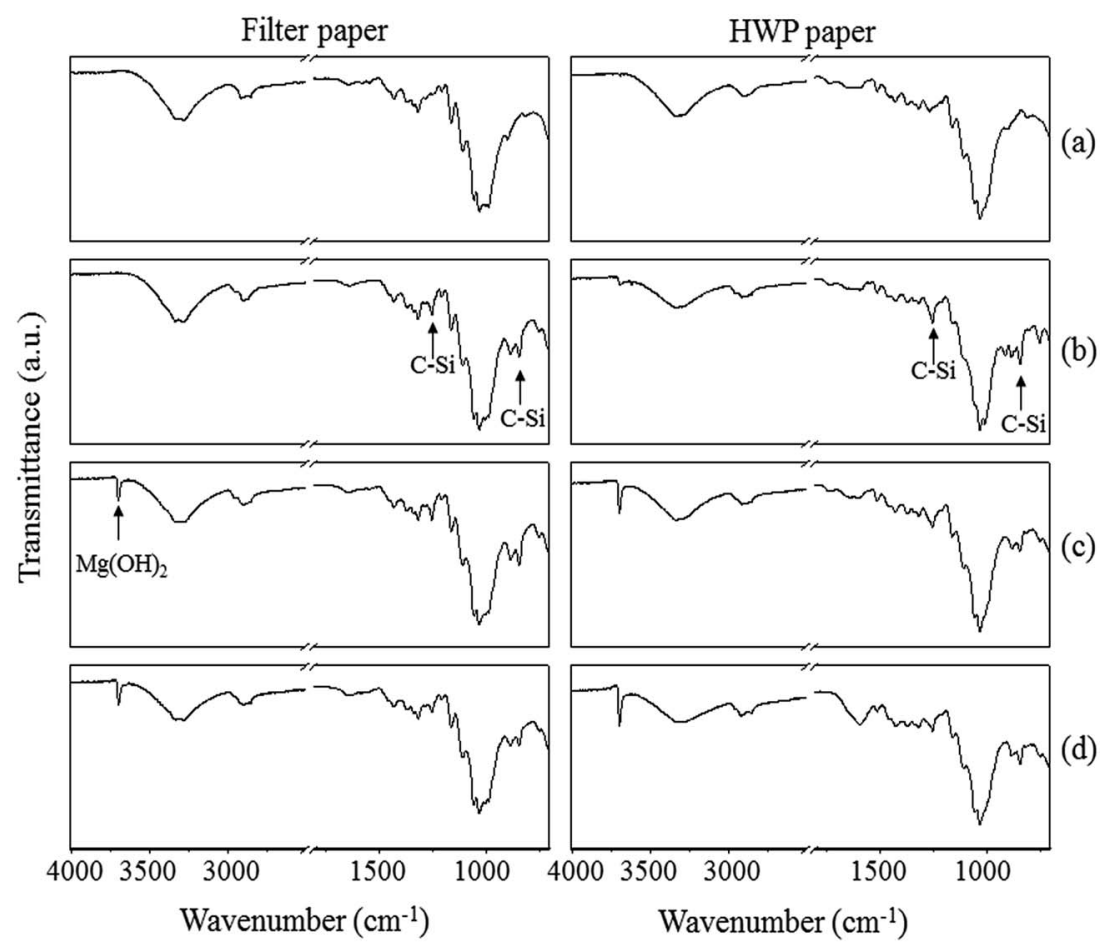

Fig. 6 ATR-IR spectra of uncoated and coated paper before and after aging. (a) uncoated paper, (b) TMSC coated before aging, (c) TMSC$\mathrm{Mg}(\mathrm{OH})_{2}$ NPs coated before aging (d) TMSC-Mg(OH) 2 NPs coated after aging. 
Table 4 Water contact angles of coated and uncoated papers before and after aging

\begin{tabular}{llr}
\hline & Filter paper & HWP paper \\
\hline Uncoated & Not measurable & $126 \pm 2$ \\
Uncoated, aged & Not measurable & $123 \pm 3$ \\
TMSC coated & $124 \pm 4$ & $128 \pm 3$ \\
TMSC coated, aged & Not measurable & $92 \pm 5$ \\
TMSC- $\mathrm{Mg}(\mathrm{OH})_{2}$ NPs coated & $133 \pm 3$ & $126 \pm 3$ \\
TMSC-Mg(OH $)_{2}$ NPs coated, aged & $140 \pm 3$ & $122 \pm 3$
\end{tabular}

sizing components giving no changes in the contact angle values. Whereas, peeled uncoated filter paper, which contains $100 \%$ pure cellulose and no sizing components, yielded (CA) $\mathrm{H}_{2} \mathrm{O}: 0^{\circ}$ (like in the case of unpeeled sample). In contrast (CA) $\mathrm{H}_{2} \mathrm{O}$ of $130 \pm 7^{\circ}$ is obtained for coated and peeled sample giving a solid evidence that the hydrophobic TMSC-Mg(OH) NPs are penetrated into inner fiber structure of the paper.

\subsection{Alkaline reserve (AR) and pH determination}

The neutralization of acids and the introduction of an alkaline reserve (AR) in paper is highly important in paper conservation to prevent or slow down further hydrolysis. The $\mathrm{pH}$ and alkaline reserve of coated and uncoated filter and HWP paper before and after aging are given in Table 5. As expected, uncoated filter paper exhibits a pH of 7 and no alkaline reserve. Interestingly the $\mathrm{pH}$ of TMSC coated papers (both filter and HWP) is increased by one unit, suggesting that TMSC coating also contributed to the $\mathrm{pH}$ increase. This is confirmed by measuring the $\mathrm{pH}$ of TMSC dispersed in pure MilliQ-water where a $\mathrm{pH}$ value of $8 \pm 0.3$ is obtained compared to the $\mathrm{pH}(7 \pm 0.1)$ of MilliQ-water without TMSC. After treatment with TMSC-Mg(OH $)_{2}$ NPs, a pH of 10 and an alkaline reserve (AR) of $47 \mathrm{meq}\left[\mathrm{OH}^{-}\right] /$ $100 \mathrm{~g}$ is reached. The AR in this case is corresponds to $1.4 \mathrm{wt} \%$ of $\mathrm{Mg}(\mathrm{OH})_{2}$. Interestingly after aging no large change in $\mathrm{pH}$ and alkaline reserve are noticed. These data fits very well to the results obtained from the EDX analysis where almost no major reduction in magnesium is noticed for paper coated with TMSC-Mg(OH $)_{2}$ mixture after aging. However, uncoated HWP paper is acidic with a $\mathrm{pH}$ of 4 as determined by $\mathrm{pH}$ measurement. Similar to filter paper, coating with TMSC did not result in any changes of alkaline reserve. By treatments of HWP paper with TMSC- $\mathrm{Mg}(\mathrm{OH})_{2}$ NPs mixture, the $\mathrm{pH}$ and the alkaline reserve are increased to 9 and $61 \mathrm{meq}\left[\mathrm{OH}^{-}\right] / 100 \mathrm{~g}$ (corresponding to $\left.1.8 \mathrm{wt} \% \mathrm{Mg}(\mathrm{OH})_{2}\right)$. Although $\mathrm{pH} 9$ can be considered as an 'unsafe' value for oxidized HWP paper that requires deacidification and an additional alkaline reserve as stated by other authors, ${ }^{2}$ the $\mathrm{pH}$ of the final coated paper can easily be tuned depending on the chosen nanoparticles concentration (see below). After aging the $\mathrm{pH}$ and the alkaline reserve are significantly decreased to 8 and $41 \mathrm{meq}\left[\mathrm{OH}^{-}\right] / 100 \mathrm{~g}($ i.e.1.2 wt\% $\mathrm{Mg}(\mathrm{OH})_{2}$ ) confirming the consumption of some $\mathrm{Mg}(\mathrm{OH})_{2}$ by neutralization reactions with acids present in HWP paper. As mentioned above, acid neutralization with $\mathrm{Mg}(\mathrm{OH})_{2}$ can possibly leads to the formation of its corresponding salt such as magnesium sulfate $\left(\mathrm{MgSO}_{4}\right)$, which does not contributes to the alkaline reserve, and therefore a less alkaline reserve is determined. As shown in Table 5 the $\mathrm{pH}$ of uncoated filter paper is 7 and it does not need deacidification. Therefore no alkaline reserve is consumed upon aging. By using TMSC-Mg(OH $)_{2} \mathrm{NPS}$ mixture it is possible to eliminate the acidity and to simultaneously introduce a sustainable alkaline reserve to paper by a very simple but efficient process.

To determine the amount of alkaline reserve (AR) deposited inside the paper sheets the coated materials from the front and back side of the paper were peeled-off, and the samples that remained after peeling were analyzed by back-titration. In addition the $\mathrm{pH}$ was measured and compared with results of the alkaline reserve (Table 6). Surprisingly an increase of $14 \mathrm{wt} \%$ $\mathrm{Mg}(\mathrm{OH})_{2}$ deposition (AR: $54 \mathrm{meq}\left[\mathrm{OH}^{-}\right] / 100 \mathrm{~g}$ ) and almost no change in $\mathrm{pH}$ are observed for filter paper after peeling one time compared to unpeeled samples, confirming that more material is deposited or diffused into the porous fiber structure of paper. Even though the thickness is reduced $36 \%$ after five times peeling as mentioned above, no significant changes in alkaline reserve and $\mathrm{pH}$ are observed. This is an evidence that the nanoparticles are equally deposited/distributed in the entire inner paper surface. However, a different behavior is observed in the case of HWP papers. After first peeling the alkaline reserve is decreased to $50 \%$ (31 meq $\left[\mathrm{OH}^{-}\right] / 100 \mathrm{~g}$ ) and remained almost constant after five times, but no major changes in $\mathrm{pH}$ are observed similar to filter paper. Overall, our coating provided an approx. $2 \mathrm{wt} \% \mathrm{Mg}(\mathrm{OH})_{2}\left(55 \mathrm{meq}\left[\mathrm{OH}^{-}\right] / 100 \mathrm{~g}\right)$ and $\mathrm{pH}$ of 11 for filter paper, and approx. $1 \mathrm{wt} \% \mathrm{Mg}(\mathrm{OH})_{2}\left(29 \mathrm{meq}\left[\mathrm{OH}^{-}\right] / 100 \mathrm{~g}\right)$ and $\mathrm{pH}$ of 8 in the case of HWP paper even after five times peeling. From the above results it can be confirmed that our treatment is highly efficient, and enabled the irreversible

Table 5 Alkaline reserve (AR in meq $\left[\mathrm{OH}^{-}\right] / 100 \mathrm{~g}$ of paper)) and $\mathrm{pH}$ of coated and uncoated paper before and after aging

\begin{tabular}{|c|c|c|c|c|c|c|}
\hline \multirow[b]{2}{*}{ Samples } & \multicolumn{3}{|c|}{ Filter paper } & \multicolumn{3}{|c|}{ HWP paper } \\
\hline & $\mathrm{pH}$ & $\mathrm{AR}$ & $\mathrm{Mg}(\mathrm{OH})_{2}(\mathrm{wt} \%)$ & $\mathrm{pH}$ & $\mathrm{AR}$ & $\mathrm{Mg}(\mathrm{OH})_{2}(\mathrm{wt} \%)$ \\
\hline Uncoated & $7 \pm 0.1$ & - & - & $4 \pm 0$ & - & - \\
\hline Uncoated, aged & $7 \pm 0.3$ & - & - & $4 \pm 0$ & - & - \\
\hline TMSC coated & $8 \pm 0.3$ & - & - & $5 \pm 0.2$ & - & - \\
\hline TMSC coated, aged & $8 \pm 0.1$ & - & - & $5 \pm 0.1$ & - & - \\
\hline TMSC-Mg(OH $)_{2}$ coated & $10 \pm 0.1$ & $47 \pm 1$ & 1.4 & $9 \pm 0.3$ & $61 \pm 6$ & 1.8 \\
\hline TMSC-Mg(OH $)_{2}$ coated, aged & $10 \pm 0.1$ & $47 \pm 2$ & 1.4 & $8 \pm 0.1$ & $41 \pm 2$ & 1.2 \\
\hline
\end{tabular}


deposition of alkaline nanoparticles not only on the surface but also at the inner paper fiber structure, which is highly important for further neutralizing the acids that can be generated during storage and preservation.

Papers were also coated with lower concentrations of TMSC- $\mathrm{Mg}(\mathrm{OH})_{2}$ NPs as shown in Section 2.3 in order to tune the final $\mathrm{pH}$ of the coated papers. At the concentration of $0.0625 \%$ $(\mathrm{w} / \mathrm{v})$ a $\mathrm{pH}$ of $7.5 \pm 0.1$ and an alkaline reserve of $3.8 \pm 0.1 \mathrm{meq}$ $\left[\mathrm{OH}^{-}\right] / 100 \mathrm{~g}$ (corresponding to $0.1 \% \mathrm{wt} \% \mathrm{Mg}(\mathrm{OH})_{2}$ ) are obtained for filter paper. Whereas in the case of HWP paper the $\mathrm{pH}$ of $7.6 \pm 0.3$ and the alkaline reserve of $9.1 \pm 0.3 \mathrm{meq}\left[\mathrm{OH}^{-}\right] / 100 \mathrm{~g}$ (corresponding to $0.3 \% \mathrm{wt} \% \mathrm{Mg}(\mathrm{OH})_{2}$ ) are reached with 8 -fold higher particles concentration $(0.25 \%(\mathrm{w} / \mathrm{v}))$. Obviously after the deacidification a neutral $\mathrm{pH}$ is obtained creating a safer environment for the papers. After aging the samples for two weeks the changes in $\mathrm{pH}$ and alkaline reserve are almost negligible for filter paper, while the decrease in $\mathrm{pH}$ and alkaline reserve are one unit and $22 \%$ for HWP paper (Table S5, see $\mathrm{ESI}^{\dagger}$ ), respectively. The outcome from these measurements is in line with the results obtained with higher particles concentration where a similar reduction in $\mathrm{pH}$ and alkaline reserve are noted upon aging.

An important issue in the paper conservation is to bring a 'safer' pH value (i.e. between 6.5-7.5) after the deacidification. ${ }^{9}$ In this context, several non-aqueous methods have been proposed to meet the above demand. For example in the recently established method by Poggi et al. an alcoholic dispersions of $\mathrm{Mg}(\mathrm{OH})_{2}$ NPs are employed to reach the final $\mathrm{pH}$ of ca.7 for the deacidified paper, with a single treatment. ${ }^{9}$ Likewise, a dispersion of magnesium oxide $(\mathrm{MgO})$ in non-polar fluorinated surfactant is used in the 'Bookkeeper' method, which allows to tune the final $\mathrm{pH}$ of the treated paper between 7 and $10 .{ }^{40}$ Wei T'O is another well-known method, which uses magnesium-methoxy methyl carbonate (MMC) solutions in ethyl or methyl alcohol and chlorofluorocarbons (CFC). ${ }^{41}$ Upon contact with water from the paper or from the surrounding atmosphere MMC is hydrolysed into reactive $\mathrm{Mg}(\mathrm{OH})_{2}$, leading to acid neutralization and formation of protective magnesium carbonate $\left(\mathrm{MgCO}_{3}\right)$ layer. This method also gives the possibility to alter the $\mathrm{pH}$ values of the deacidified papers from 7.5 to 10.4. It is obvious that the final $\mathrm{pH}$ of the treated paper can be easily tuned from neutral to high $\mathrm{pH}$ (10) by the above mentioned methods. These results, in general, are comparable with the $\mathrm{pH}$ values (between 7.6 and 9 depending on the chosen particles concentration) obtained by our treatment that employed also $\mathrm{Mg}(\mathrm{OH})_{2}$ NPs, which are stabilized in TMSC/HMDSO. The different deacidification methods described above are very efficient in acid neutralization and providing additional alkaline reserve that prevents papers from further degradation. However, nanoparticles of $\mathrm{Mg}(\mathrm{OH})_{2}$ stabilized in TMSC/ HMDSO or alcohol offer certain advantages than the above mentioned methods and do not give the possible drawbacks owing to the use of fluorinated surfactants or fluorocarbons for the stabilization of deacidifying agents. Moreover, the longterm effect of fluorinated surfactants or hydrocarbons that is present on the paper after the deacidification have not been investigated in detail until now.

\subsection{Mechanical strength determination}

In addition to the introduction of an alkaline reserve and the neutralization of acids, strengthening of old and brittle paper is of high interest. Therefore, we investigated the role of TMSC in the improvement of mechanical properties such as tensile strength and tensile strain at break. The hypothesis would be that TMSC or cellulose formed out of it would result in an increased fiber-fiber bond and therefore higher tensile strengths. The mechanical properties of uncoated and treated filter and HWP paper are shown in Fig. 7. A significant improvement in tensile strength and strain at break is obvious after coating with TMSC and TMSC/Mg(OH $)_{2}$. Upon TMSC coating, the increase in tensile strength at maximum for both filter and HWP paper is nearly 15\%. Mixtures of TMSC- $\mathrm{Mg}(\mathrm{OH})_{2}$ resulted in a reduction of strength for filter paper whereas the strength of HWP paper coated with particles and polymer is similar to pure TMSC coatings. More significantly the tensile strain at break is increased up to $18 \%$ for filter paper after TMSC coating and by $6 \%$ for HWP paper. TMSC also increases the Young modulus of the paper (Table S6, see ESI $\dagger$ ), an indication that the paper becomes stiff. However, the application of TMSC-Mg(OH $)_{2}$ NPs decreased the stiffness i.e. increased elasticity, as shown by the reduced Young modulus. Imparting elasticity is highly beneficial in particular to HWP paper, which are rigid and brittle. In all cases, after aging a lower Young modulus is noted except for uncoated HWP paper. The TMSC- $\mathrm{Mg}(\mathrm{OH})_{2}$ coatings lead to $74 \%$ increase in the tensile strain at break for filter paper and 13\% increase for HWP paper, which is an indication that the compact mixture of particles and polymers on and in the fibers matrix have a profound impact on the mechanical properties. After aging, the tensile strengths of uncoated papers are decreased (14\% for filter and 30\% for HWP paper), and also in the case of TMSC coated papers. TMSC-Mg(OH $)_{2}$ coated papers showed less reduction in strength ( $9 \%$ for filter paper, $0.5 \%$ for HWP paper).

Table 6 Alkaline reserve (AR in meq $\left[\mathrm{OH}^{-}\right] / 100 \mathrm{~g}$ of paper)) and $\mathrm{pH}$ of TMSC-Mg(OH) $)_{2} \mathrm{NPs}$ coated HWP paper before and after peeling

\begin{tabular}{|c|c|c|c|c|c|c|}
\hline \multirow[b]{2}{*}{ Peel } & \multicolumn{3}{|c|}{$\underline{\text { Filter paper }}$} & \multicolumn{3}{|c|}{ HWP paper } \\
\hline & $\mathrm{AR}$ & $\mathrm{Mg}(\mathrm{OH})_{2} \mathrm{wt} \%$ & $\mathrm{pH}$ & $\mathrm{AR}$ & $\mathrm{Mg}(\mathrm{OH})_{2} \mathrm{wt} \%$ & $\mathrm{pH}$ \\
\hline 1 & $54 \pm 3$ & 1.6 & $11 \pm 0.1$ & $31 \pm 5$ & 0.9 & $8 \pm 0.2$ \\
\hline 5 & $55 \pm 9$ & 1.6 & $11 \pm 0.1$ & $29 \pm 1$ & 0.8 & $8 \pm 0.1$ \\
\hline
\end{tabular}



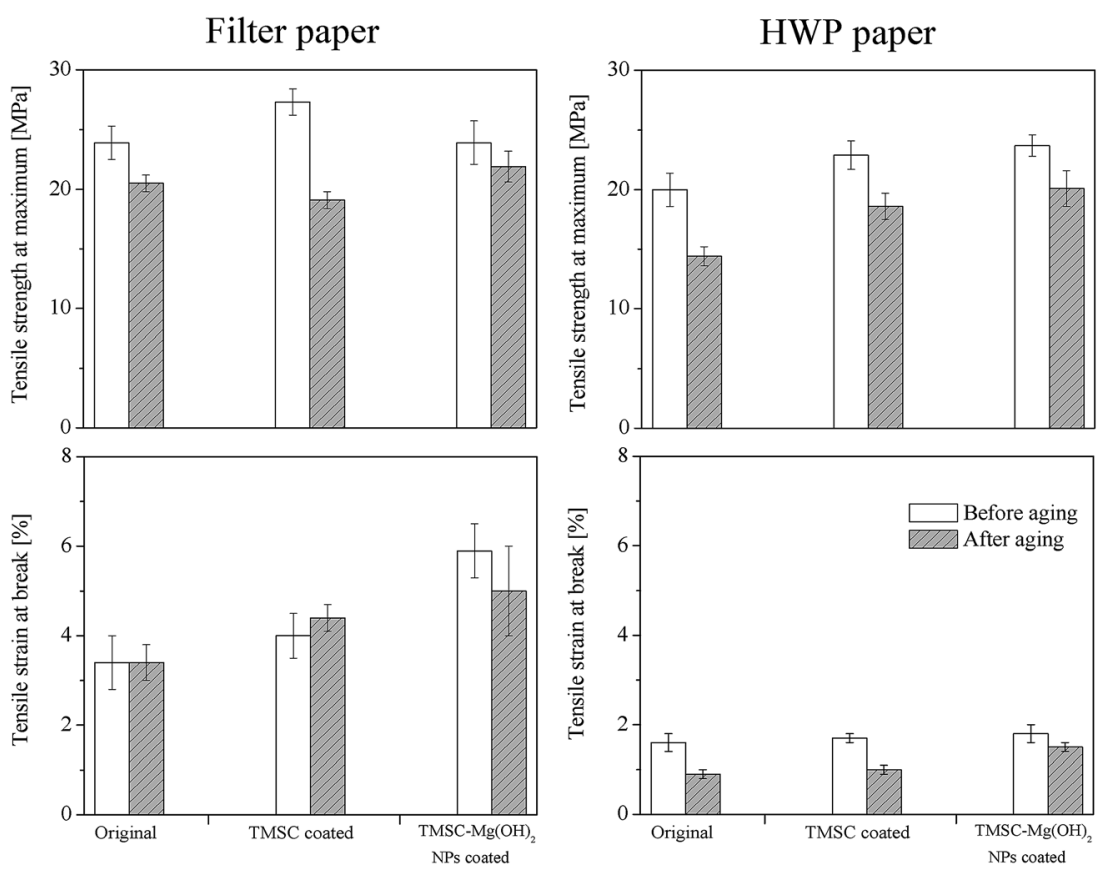

Fig. 7 Tensile strength at maximum and tensile strain at break of coated and uncoated paper before and after aging.

These results illustrate that treatment with TMSC-Mg(OH $)_{2}$ prevents further disintegration of paper upon aging and stabilizes the mechanical properties of paper. On the whole, it is an indication that the addition of TMSC and particles show a good compatibility with paper and improve the mechanical properties.

\section{Conclusions}

We have demonstrated a simple and highly efficient deacidification method which simultaneously neutralizes acids, creates an alkaline reserve and improves the mechanical properties of filter and HWP paper. The application of trimethylsilyl cellulose (TMSC) strongly increases the colloidal stability of $\mathrm{Mg}(\mathrm{OH})_{2}$ nanoparticles in the organic solvent hexamethyldisiloxane (HMDSO). Coating of these dispersions on papers results in thin, invisible hydrophobic alkaline layers that do not influence the appearance of non-aged and aged papers. The nanocoatings significantly increase the $\mathrm{pH}$ and alkaline reserve and result in higher tensile strengths before and after aging. Even though the effect of TMSC or TMSC- $\mathrm{Mg}(\mathrm{OH})_{2}$ coating on the degree of polymerization of the papers before and after aging is not analyzed in this work, this important parameter is essential to comprehend the degradation properties paperbased materials, which will be determined and published elsewhere. The method and treatment procedure is versatile and can be extended to other kinds of cellulose-based materials. As a final remark the nanoparticles coated with hydrophobic TMSC protective layer can be less dangerous, environmentally friendly and could reduce the health risk, which can be probably caused by usage of pure nanoparticles.

\section{Acknowledgements}

The authors gratefully acknowledge financial supports from the Austrian Research Promotion Agency (FFG) and the Austrian Agency for International Cooperation in Education and Research (OeAD). Dr Damien Faivre acknowledges funding from the European research council (Project MB2 no. 256915). Dr Alenka Ojstrsek and Mojca Bozic from the University of Maribor, Slovenia are greatly acknowledged for their support regarding the colorimetric measurements.

\section{References}

1 P. Baglioni, D. Chelazzi, R. Giorgi and G. Poggi, Langmuir, 2013, 29, 5110-5122.

2 J. W. Baty, C. L. Maitland, W. Minter, M. A. Hubbe and S. K. Jordan-Mowery, BioResources, 2010, 5, 1955-2023.

3 Z. Souguir, A.-L. Dupont, K. Fatyeyeva, G. Mortha, H. Cheradame, S. Ipert and B. Lavedrine, RSC Adv., 2012, 2, 7470-7478.

4 D. Klemm, B. Heublein, H.-P. Fink and A. Bohn, Angew. Chem., Int. Ed., 2005, 44, 3358-3393.

5 R. Babu, K. O'Connor and R. Seeram, Prog. biomater., 2013, 2, 8.

6 D. Klemm, B. Philipp, T. Heinze, U. Heinze and W. Wagenknecht, in Comprehensive cellulose Chemsitry: fundamental and analytical methods, Wiley-VCH, 1998.

7 M. Whitmore Paul and J. Bogaard, in Restaurator, 1994, vol. 15, p. 26.

8 X. Zou, N. Gurnagul, T. Uesaka and J. Bouchard, Polym. Degrad. Stab., 1994, 43, 393-402. 
9 G. Poggi, R. Giorgi, N. Toccafondi, V. Katzur and P. Baglioni, Langmuir, 2010, 26, 19084-19090.

10 G. Poggi, N. Toccafondi, L. N. Melita, J. C. Knowles, L. Bozec, R. Giorgi and P. Baglioni, Appl. Phys. A, 2014, 114, 685-693.

11 Z. Souguir, A.-L. Dupont, J.-B. d'Espinose de Lacaillerie, B. Lavédrine and H. Cheradame, Biomacromolecules, 2011, 12, 2082-2091.

12 C. Piovesan, A.-L. Dupont, I. Fabre-Francke, O. Fichet, B. Lavédrine and H. Chéradame, Cellulose, 2014, 21, 705715.

13 E. Stefanis and C. Panayiotou, in Restaurator, 2010, vol. 31, p. 19.

14 L. Botti, O. Mantovani, A. Orrù Maria and D. Ruggiero, in Restaurator, 2006, vol. 27, p. 9.

15 E. Stefanis and C. Panayiotou, in Restaurator, 2008, vol. 29, p. 125.

16 Battelle-Institut, German pat., No. DE 4104515 C1, 1992.

17 H. Cheradame, Int Preserv News, 2009, vol. 48, pp. 5-8.

18 R. Kargl, T. Mohan, M. Bračič, M. Kulterer, A. Doliška, K. Stana-Kleinschek and V. Ribitsch, Langmuir, 2012, 28, 11440-11447.

19 T. Mohan, R. Kargl, A. Doliška, A. Vesel, S. Köstler, V. Ribitsch and K. Stana-Kleinschek, J. Colloid Interface Sci., 2011, 358, 604-610.

20 T. Mohan, S. Spirk, R. Kargl, A. Doliška, H. M. A. Ehmann, S. Köstler, V. Ribitsch and K. Stana-Kleinschek, Colloids Surf., A, 2012, 400, 67-72.

21 E. Kontturi, P. C. Thüne and J. W. Niemantsverdriet, Langmuir, 2003, 19, 5735-5741.

22 D. Breitwieser, M. Kriechbaum, H. M. A. Ehmann, U. Monkowius, S. Coseri, L. Sacarescu and S. Spirk, Carbohydr. Polym., 2015, 116, 261-266.

23 R. Giorgi, C. Bozzi, L. Dei, C. Gabbiani, B. W. Ninham and P. Baglioni, Langmuir, 2005, 21, 8495-8501.

24 R. Giorgi, L. Dei, M. Ceccato, C. Schettino and P. Baglioni, Langmuir, 2002, 18, 8198-8203.

25 P. A. Hassan, S. Rana and G. Verma, Langmuir, 2014, 31, 312.
26 D. Fakin, N. Veronovski, A. Ojstršsek and M. Božič, Carbohydr. Polym., 2012, 88, 992-1001.

27 D. Fakin, K. Stana Kleinschek, M. Kurečič and A. Ojstršek, Surf. Coat. Technol., 2014, 253, 185-193.

28 K. Liu, Y. Xu, X. Lin, L. Chen, L. Huang, S. Cao and J. Li, Carbohydr. Polym., 2014, 110, 382-387.

29 A. D. Pomogailo and V. N. Kestelman, Metallopolymer Nanocomposites, ed. R. Hull, R. M. Osgood, Jr, J. Parisi and H. Warlimont, Springer, Berlin, Heidelberg, 2005, vol. 81, pp. 65-113.

30 R. B. Grubbs, Polym. Rev., 2007, 47, 197-215.

31 Y. Liu, S. Z. D. Cheng, X. Wen and J. Hu, Langmuir, 2002, 18, 10500-10502.

32 J. Jiang, G. Oberdörster and P. Biswas, J. Nanopart. Res., 2009, 11, 77-89.

33 M. R. Kulterer, V. E. Reichel, R. Kargl, S. Köstler, V. Sarbova, T. Heinze, K. Stana-Kleinschek and V. Ribitsch, Adv. Funct. Mater., 2012, 22, 1749-1758.

34 S. Elzey and V. Grassian, J. Nanopart. Res., 2010, 12, 19451958.

35 A. Mosca Conte, O. Pulci, A. Knapik, J. Bagniuk, R. Del Sole, J. Lojewska and M. Missori, Phys. Rev. Lett., 2012, 108, 158301.

36 M. Cristina Area and H. Cheradame, BioResources, 2011, 6, 5304-5337.

37 L. Taajamaa, E. Kontturi, J. Laine and O. J. Rojas, J. Mater. Chem., 2012, 22, 12072-12082.

38 M. Bracic, T. Mohan, R. Kargl, T. Griesser, S. Hribernik, S. Kostler, K. Stana-Kleinschek and L. Fras-Zemljic, RSC Adv., 2014, 4, 11955-11961.

39 T. Mohan, S. Spirk, R. Kargl, A. Doliska, A. Vesel, I. Salzmann, R. Resel, V. Ribitsch and K. Stana-Kleinschek, Soft Matter, 2012, 8, 9807-9815.

40 Preservation Technologies Website - Bookkeeper FAQ section, http:/www.ptlp.com/fag.html, accessed Feb 25, 2015.

41 R. D. Smith, Conservation of Library and Archive Materials and the Graphic Arts, Butteworth, London, 1987. 